\title{
Endothelin-1 predicts incident diabetic peripheral neuropathy in Type 2 Diabetes: a cohort study
}

\section{Sharon Li Ting Pek ${ }^{1}$, Su Chi Lim ${ }^{1,2,3,5}$, Keven Ang', Pek Yee Kwan', Wern Ee Tang4, Chee Fang Sum ${ }^{2,3}$ and Subramaniam Tavintharan ${ }^{1,2,3}$}

${ }^{1}$ Clinical Research Unit, Khoo Teck Puat Hospital, Singapore, Singapore, ${ }^{2}$ Diabetes Centre, Admiralty Medical Centre, Singapore, Singapore, ${ }^{3}$ Division of Endocrinology. Khoo Teck Puat Hospital, Singapore, Singapore, ${ }^{4}$ Yishun Polyclinic, National Healthcare Group, Singapore, Singapore, and ${ }^{5}$ Saw Swee Hock School of Public Health, Singapore, Singapore
Correspondence should be addressed to S Tavintharan Email subramaniam.tavintharan@ ktph.com.sg

\begin{abstract}
Introduction: Diabetic peripheral neuropathy (DPN) is a common microvascular complication in patients with type 2 diabetes (T2D). Apart from hyperglycemia, few modifiable risk factors have been identified. Endothelin-1 is a potent vasoconstrictor peptide, implicated in the causal pathway of microangiopathy. We investigated whether baseline plasma endothelin-1 and other metabolic and vascular risk factors predicted the incidence of DPN.

Design: This is a 3-year observational, cohort study.

Methods: In patients with T2D ( $n=2057)$, anthropometric data, fasting blood, and urine were collected for biochemistry and urine albumin/creatinine measurements. Forearm cutaneous endothelial reactivity was assessed by iontophoresis and laser Doppler flowmetry/imaging. Measurements were repeated on follow-up. Incident DPN was considered present if an abnormal finding in monofilament ( $<8$ of 10 points) or neurothesiometer testing was $\geq 25$ volts on either foot at 3-year follow-up, but normal at baseline. Plasma endothelin-1 was assessed by ELISA.

Results: At baseline, mean age of patients was $57.4 \pm 10.8$ years old and prevalence of DPN was $10.8 \%$. Of the 1767 patients without DPN, 1250 patients returned for follow-up assessment $((2.9 \pm 0.7)$ years $)$, with a $10.7 \%$ incidence of DPN. Patients with incident DPN had significantly higher baseline endothelin-1 (1.43 (1.19-1.73) vs 1.30 (1.06-1.63)) $\mathrm{pg} / \mathrm{mL}, P<0.0001$. Multivariable Cox proportional hazards ratio showed a 1-s.D. increase in log endothelin-1 (adjusted HR: 4.345 (1.451-13.009), $P=0.009)$, systolic blood pressure (per 10-unit) (adjusted HR: $1.107(1.001-1.223), P=0.047)$ and diabetes duration (adjusted HR: 1.025 (1.004-1.047), $P=0.017$ ) predicted incident DPN, after adjustment for glycemic control, eGFR, albuminuria, peripheral arterial disease and retinopathy status.

Conclusion: Higher baseline endothelin-1, blood pressure and diabetes duration were significant and independent predictors for incident DPN. Validation of our findings in independent cohorts and molecular mechanistic studies will help better our understanding on the role of endothelin-1 in DPN.
\end{abstract}

\section{Introduction}

Prevalence of type 2 diabetes mellitus (T2D) is increasing globally and has been identified as the ninth major cause of reduced life expectancy (1). Diabetic peripheral neuropathy (DPN) is one of the common microvascular complications

https://eje.bioscientifica.com https://doi.org/10.1530/EJE-19-0523
(C) 2020 European Society of Endocrinology Printed in Great Britain in patients with $\mathrm{T} 2 \mathrm{D}$, resulting in peripheral nerve dysfunction, accompanied with typical characteristics of pain and numbness $(2,3)$. DPN is one of the leading causes of lower limb amputations and morbidity in the 
world. Aggressive glucose-lowering has been shown to be effective in delaying onset of DPN for type 1 diabetes but less so in T2D (4), probably arising from differences in their aetiology, where T2D is characterized by defects in insulin resistance, $\beta$-cell failure and pathophysiologic abnormalities in multiple organs (5). Comparing patients with intensified multifactorial intervention and those on conventional care, the STENO-2 study showed significant relative risk reductions for autonomic neuropathy, nephropathy and retinopathy (6), but no changes in the progression of DPN was observed.

Patients with DPN have microvascular dysfunction, as evidenced by reduced endothelial-dependent and endothelial-independent vasodilation (7). Impairment of endothelial function, characterized by reduced bioactivity of nitric oxide (NO), is an early finding in patients with insulin resistance (8) and T2D (9). Early alterations in microcirculation have been identified in pre-diabetic states, suggesting that endothelial dysfunction occurs early in the diabetes pathway (10). We showed in a previous cross-sectional study that reduced endothelialdependent vasodilation and apolipoprotein C3 were significantly associated with DPN (11).

Endothelin-1 is a potent vasoconstrictor and proinflammatory peptide produced from various cell types, including the endothelial (12), neuronal (13) and renal tubular cells (14). Endothelin-1 acts on endothelin-1 receptors, $\mathrm{ET}_{\mathrm{A}}$ and $\mathrm{ET}_{\mathrm{B}}$ receptors, on adjacent endothelial or smooth-muscle cells, producing either vasoconstrictive or vasodilative effects, respectively. A large body of evidence has implicated endothelin-1 to be in the causal pathway of diabetic microangiopathy. Besides the negative effects on NO availability, insulin-resistant states such as T2D (15), obesity (16), essential hypertension (17) and coronary artery disease (18) have been shown to be associated with elevated plasma levels of endothelin-1.

While higher plasma endothelin-1 has been reported in patients with DPN compared to those without, these studies were conducted in a cross-sectional manner and causality of endothelin-1 to DPN is unknown. We hypothesize that in patients with T2D, higher baseline endothelin-1 predicts incident DPN. The aim of the study was to determine if baseline clinical parameters and plasma endothelin-1 are predictive of incident DPN.

\section{Methods}

This is a cohort study, where patients were recruited from August 2011 to March 2014 (SMART2D: Singapore study of MAcro-angiopathy and micro-vascular Reactivity in Type 2 Diabetes) and followed-up after 3 years, as described previously $(19,20)$. We consecutively enrolled adults between 21 and 90 years of age, with T2D seen in our institution's Diabetes Centre and a community medical centre in Singapore. Patients were re-contacted through phone calls or mails. All procedures, performed at baseline, were repeated at follow-up. This study was approved by our institutional Ethics Review Board (NHG Domain Specific Review Board), and all participants signed informed consent at both visits.

Anthropometric data, fasting blood and urine were collected for blood biochemistry, urine albumin and creatinine measurements (Roche, Diagnostics) at both baseline and follow-up in the same routine laboratory. All blood samples were centrifuged within $1 \mathrm{~h}$ after collection and kept at $4^{\circ} \mathrm{C}$ during this period. Thereafter, they were stored at $-80^{\circ} \mathrm{C}$ in aliquots and used without additional freeze-thaw cycles. Patients were advised not to take their morning medications until fasting blood was obtained. Estimated GFR (eGFR) was calculated using the Chronic Kidney Disease Epidemiology Collaboration (CKD-EPI) equation (21). Blood pressure (BP) and heart rate (Omron, Japan) were measured at the clinic and the average of three most consistent readings was taken. Baseline plasma endothelin-1 and insulin were measured by ELISA (RnD systems, USA and Mercodia, Sweden, respectively). Plasma samples were measured in duplicates with intra-assay CV of $2.02 \%$ and $2.83 \%$ and inter-assay CV of $8.00 \%$ and $7.40 \%$ for endothelin- 1 and insulin, respectively. The homeostasis model assessment (HOMA)-2 of insulin resistance (HOMA2-IR) was calculated using an excel-based HOMA index of insulin resistance (HOMA2-IR) obtained from (https://www.dtu.ox.ac.uk/ homacalculator/) (22). Assessment for neuropathy was by a neurothesiometer (Horwell Scientific, Yorkshire, UK) for vibration and with a 10-g monofilament for light touch. DPN was present if an abnormal finding in monofilament (inability to detect more than 2 of 10 points on either foot) or neurothesiometer testing of $\geq 25$ volts on either foot was detected. The outcome in this study is incident DPN. Baseline and follow-up foot examinations were performed by the same team of research nurses $(n=4) \quad$ who received standardized training and accreditation (11).

\section{Vascular measurements}

Microvascular endothelial function assessments were performed in temperature controlled rooms by laser 
Doppler flowmetry/imaging (Lisca PIM 3.0, Lisca Development AB, Linkoping, Sweden) to measure cutaneous perfusion, accompanied by iontophoresis of acetylcholine or sodium nitroprusside to assess endothelium-dependent and endothelium-independent vasodilation, respectively, as described previously (23). Vasodilation was presented as percentage change from baseline flowmetry. Similarly, the same team performed both baseline and follow-up measurements.

\section{Statistical analyses}

All analyses were performed using SPSS version 22 (SPSS Inc) and STATA SE 14. Results for continuous variables with normal distribution were presented in mean \pm S.D.; medians and interquartile ranges were presented for continuous but non-normally distributed variables. Binary variables were presented as absolute numbers or in percentages. Binary and continuous variables with normal distribution were analyzed using Chi-square and Student's t-test or ANOVA, respectively, while nonparametric tests were used for quantitative variables not normally distributed. Bonferroni correction was used for multiple testing. Bivariate associations of log-transformed endothelin-1 with clinical variables were analyzed using Pearson analyses. Associations of independent variables with endothelin-1 were analyzed using multivariable generalized linear regression. Only variables significant in Pearson's correlation (baseline age, BMI, HDL-C, triglyceride, systolic blood pressure, eGFR, urine ACR, retinopathy, endothelium-dependent, endotheliumindependent vasodilation and metforminusage) or known confounders (gender and ethnicity) were added into the multivariable model. Multivariable Cox proportional hazards model was used to estimate the coefficient $(\beta)$ and hazards ratio (HR) for incident DPN and 95\% CI for each risk factor assessed at baseline, after adjustment. Age, gender, ethnicity, metabolic derangements (diabetes duration, baseline $\mathrm{HbA1c}$ and systolic BP), which were significant in the univariate analysis, baseline eGFR, urinary ACR, PAD, and retinopathy status, the main diabetic complications, were included as covariates in the Cox model. Proportionality assumptions were tested using Schoenfeld residuals. Skewed data such as triglycerides, urinary ACR, endothelial-dependent and endothelial-independent vasodilation were analyzed after logarithmic transformation. All statistical tests were two-sided with a level of significance being $<0.05$.

\section{Results}

A total of 2057 patients with T2D were recruited at baseline. Prevalence of DPN was $10.8 \%$ in the cross-sectional cohort, as reported previously (11). Of 1767 patients without DPN at baseline (August 2011-March 2014), 1250 patients returned for a follow-up assessment within a mean of $(2.9 \pm 0.7)$ years. One hundred and thirty-four (10.7\%) patients developed incident DPN. Characteristics of patients with no DPN at baseline, comparing those with incident DPN and those who remained free of DPN, are shown in Table 1 and follow-up characteristics of the cohort are shown in Supplementary Table 1 (see section on supplementary materials given at the end of this article). Prevalence of patients, who were lost to follow-up, was not statistically significantly different between patients with and without DPN, at baseline (Supplementary Fig. 1). Patients, with incident DPN, were significantly older at baseline, had longer duration of T2D, had poorer glycemic control with higher baseline fasting glucose and HbA1c, Systolic BP (SBP), heart rate, poorer eGFR, higher urine ACR, poorer endothelium-independent vasodilation and higher Endothelin-1 (1.30 (1.06 - 1.63) vs 1.43 (1.19 1.73) $\mathrm{pg} / \mathrm{mL}, P<0.0001)$. At baseline, a higher proportion of patients with incident DPN were on insulin and aspirin (Table 1).

Bivariate analyses of plasma endothelin-1 is shown in Table 2 (left column). Women had lower plasma endothelin-1 (1.35 (1.08-1.67)) pg/mL levels, compared to men $(1.38(1.11-1.70)) \mathrm{pg} / \mathrm{mL}(P=0.07)$. Malays had significantly higher endothelin-1 (1.45 (1.18-1.77)) pg/mL compared to Chinese (1.33 (1.07-1.66)) pg/mL, Indians (1.35 (1.11-1.67)) $\mathrm{pg} / \mathrm{mL}$ and other ethnicities (1.27 (1.06-1.66) $) \mathrm{pg} / \mathrm{mL}(P<0.0001)$. Patients with proliferative retinopathy and non-proliferative retinopathy had significantly higher endothelin-1 than those without retinopathy $(1.44(1.19-1.78)$ vs $1.42(1.15-1.69)$ vs 1.32 (1.07-1.65)) pg/mL, $P<0.0001$, respectively. Patients on metformin had significantly lower endothelin-1 (Supplementary Table 3). In the multivariable linear regression model (Table 2, right), age, Malay ethnicity, BMI, log-triglycerides and eGFR remained significant determinants of log-transformed endothelin-1, after adjusting for gender, HDL-C, SBP, urine ACR, retinopathy, endothelium-dependent, independent vasodilation and metformin usage. When endothelium-dependent and independent vasodilation were entered into the model separately, endothelium-dependent vasodilation but not endothelium-independent vasodilation was 
Table 1 Baseline characteristics of patients with and without incident DPN $(n=1250)$.

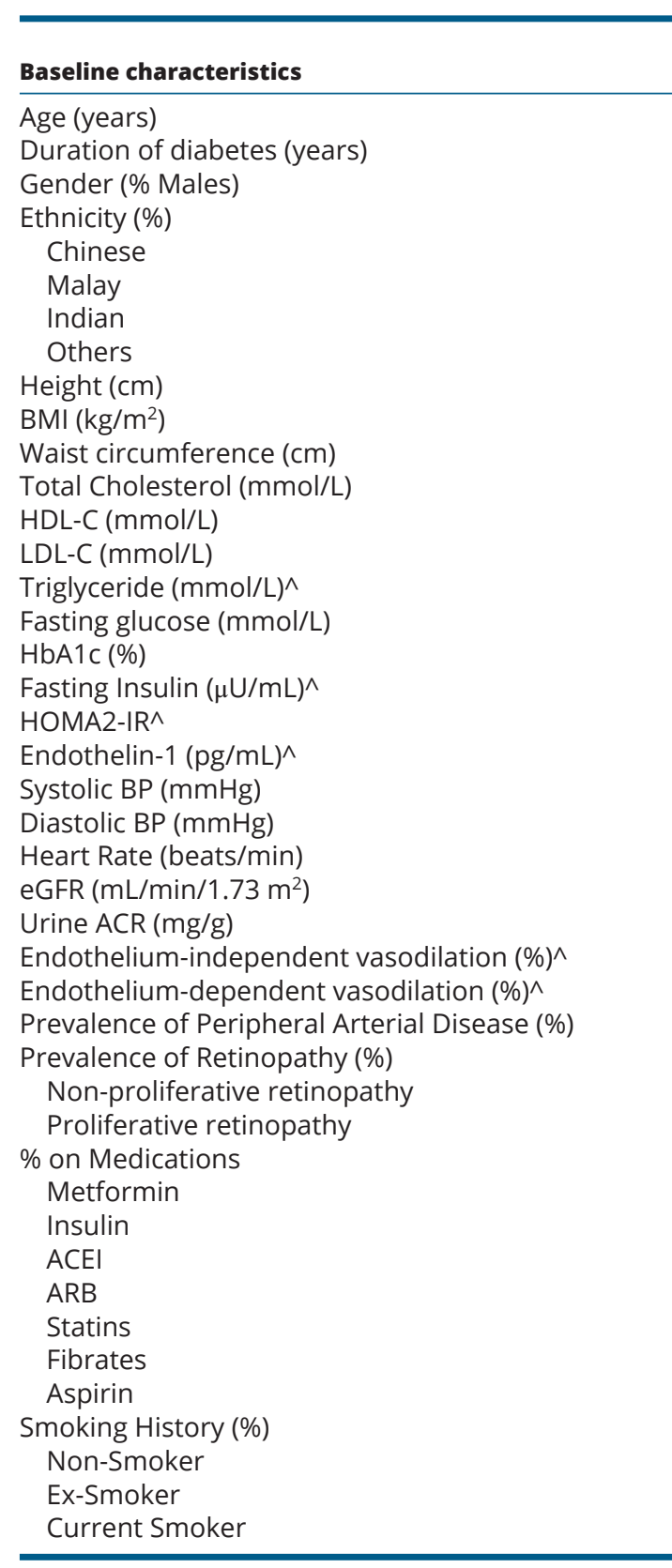

\begin{tabular}{c}
\hline No DPN on follow-up \\
\hline$(n=1116)$ \\
\hline $56.3 \pm 10.4$ \\
$10.1 \pm 8.2$ \\
48.9
\end{tabular}

55.5

18.2

22.6

3.7

$1.61 \pm 0.09$

$27.6 \pm 5.1$

$96.5 \pm 15.0$

$4.42 \pm 1.01$

$1.31 \pm 0.36$

$2.74 \pm 0.79$

$1.37(1.02-1.93)$

$7.94 \pm 2.53$

$7.67 \pm 1.27$

$7.68(4.58-12.5)$

$1.15(0.64-1.90)$

$1.30(1.06-1.63)$

$135.2 \pm 17.1$

$77.5 \pm 9.4$

$70.1 \pm 10.7$

$90.6 \pm 23.1$

$17.0(5.0-63.5)$

$71(41-110)$

$110(52-178)$

10.2

15.9

6.2

84.4

22.3

34.6

24.7

80.0

10.6

19.6

85.8

6.2

8.1

\begin{tabular}{|c|c|}
\hline Incident DPN & \\
\hline$(n=134)$ & P-value \\
\hline $59.6 \pm 9.1$ & $<0.0001$ \\
\hline $13.9 \pm 9.8$ & $<0.0001$ \\
\hline \multirow[t]{2}{*}{58.2} & 0.025 \\
\hline & 0.971 \\
\hline \multicolumn{2}{|l|}{54.5} \\
\hline \multicolumn{2}{|l|}{17.9} \\
\hline \multicolumn{2}{|l|}{23.1} \\
\hline \multicolumn{2}{|l|}{4.5} \\
\hline $1.63 \pm 0.09$ & 0.016 \\
\hline $27.4 \pm 5.6$ & 0.714 \\
\hline $95.8 \pm 14.9$ & 0.684 \\
\hline $4.48 \pm 1.11$ & 0.586 \\
\hline $1.25 \pm 0.32$ & 0.057 \\
\hline $2.80 \pm 0.98$ & 0.429 \\
\hline $1.46(1.06-2.19)$ & 0.094 \\
\hline $8.48 \pm 2.75$ & 0.017 \\
\hline $7.98 \pm 1.43$ & 0.031 \\
\hline $8.00(4.2-14.1)$ & 0.704 \\
\hline $1.16(0.81-2.12)$ & 0.123 \\
\hline $1.43(1.19-1.73)$ & $<0.0001$ \\
\hline $142.6 \pm 20.7$ & $<0.0001$ \\
\hline $78.1 \pm 10.0$ & 0.492 \\
\hline $72.3 \pm 11.7$ & 0.025 \\
\hline $75.8 \pm 30.4$ & $<0.0001$ \\
\hline $41.0(10.0-221.0)$ & $<0.0001$ \\
\hline $54(29-91)$ & 0.002 \\
\hline $89(50-151)$ & 0.083 \\
\hline \multirow[t]{2}{*}{17.3} & 0.003 \\
\hline & $<0.0001$ \\
\hline \multicolumn{2}{|l|}{20.5} \\
\hline \multicolumn{2}{|l|}{18.1} \\
\hline 73.1 & 0.001 \\
\hline 41.8 & $<0.0001$ \\
\hline 39.6 & 0.149 \\
\hline 30.3 & 0.100 \\
\hline 78.2 & 0.267 \\
\hline 8.2 & 0.241 \\
\hline \multirow[t]{2}{*}{27.6} & 0.021 \\
\hline & 0.143 \\
\hline \multicolumn{2}{|l|}{79.5} \\
\hline \multicolumn{2}{|l|}{9.8} \\
\hline \multicolumn{2}{|l|}{10.6} \\
\hline
\end{tabular}

$\wedge$ Log transformed before analysis.

statistically significant for log-transformed Endothelin-1 (Supplementary Table 2).

In the multivariable Cox regression (Table 3 ), baseline log-transformed endothelin-1 $\quad(\beta=1.469, \quad \mathrm{SE}=0.559$, $P=0.009) \mathrm{SBP}(\beta=0.101, \mathrm{SE}=0.051, P=0.047)$ and duration of diabetes $(\beta=0.025, \mathrm{SE}=0.011, P=0.017)$ remained significant predictors of incident DPN, after adjustment for age, gender, ethnicity, HbA1c, eGFR, urine ACR, PAD and retinopathy status at baseline. Baseline endothelin-1 and SBP remained as significant predictors, even after inclusion of BP medication usage (ACE inhibitors and angiotensin receptor blockers) (Supplementary Table 4).

\section{Discussion}

In this observational longitudinal cohort study, with 3-year follow-up, we show that elevated baseline endothelin-1, baseline SBP and longer duration of diabetes predicted incident DPN in a relatively large cohort of patients with 
Table 2 Univariable and multivariable association of plasma endothelin-1 (log transformed) with anthropometric and biochemical parameters $(n=1250)$.

\begin{tabular}{l}
\hline Baseline characteristics \\
\hline Age (years) \\
Duration of Diabetes (years) \\
Gender\# \\
Ethnicity \\
$\quad$ Malay \\
$\quad$ Indian \\
$\quad$ Others \\
BMI (kg/m²) \\
Waist circumference (cm) \\
Total Cholesterol (mmol/L) \\
HDL-C (mmol/L) \\
LDL-C (mmol/L) \\
Triglyceride (mmol/L)^ \\
Fasting glucose (mmol/L) \\
HbA1c (\%) \\
Fasting Insulin^ \\
HOMA-2IR^ \\
Systolic BP (mmHg) \\
Diastolic BP (mmHg) \\
eGFR (mL/min/1.73 m²) \\
Urine ACR (mg/g)^ \\
PAD\#\# \\
Retinopathy* \\
Non-proliferative \\
Proliferative \\
Endothelium-independent vasodilation (\%) \\
Endothelium-dependent vasodilation (\%) \\
Metformin (Usage vs non-usage** \\
(m)
\end{tabular}

\begin{tabular}{c}
\hline Pearson correlation \\
\hline 0.152 \\
0.028 \\
0.043 \\
0.020
\end{tabular}

\begin{tabular}{c}
\hline P-value \\
\hline$<0.0001$ \\
0.244 \\
0.07 \\
0.396
\end{tabular}

\begin{tabular}{ccc}
\hline Adjusted odds ratio $(95 \% \mathrm{Cl})$ & & P-value \\
\hline $1.002(1.001-1.002)$ & & $<0.0001$ \\
$1.016(1.000-1.032)$ & & 0.053
\end{tabular}

$1.027(1.008-1.047)$

$1.008(0.990-1.026) \quad 0.399$

$0.992(0.957-1.029) \quad 0.682$

$\begin{array}{rc}0.151 & <0.0001 \\ 0.130 & <0.0001 \\ 0.047 & 0.049 \\ -0.067 & 0.005 \\ 0.059 & 0.223 \\ 0.114 & <0.0001 \\ 0.013 & 0.589 \\ -0.005 & 0.832 \\ 0.007 & 0.763 \\ 0.002 & 0.936 \\ 0.099 & <0.0001 \\ -0.004 & 0.865 \\ -0.24 & <0.0001 \\ 0.138 & <0.0001 \\ -0.026 & 0.276 \\ 0.099 & <0.0001\end{array}$

$1.005(1.003-1.006)$

$<0.0001$

Waist circumference $(\mathrm{cm})$

Total Cholesterol $(\mathrm{mmol} / \mathrm{L})$

0.130

$1.006(0.982-1.030)$

0.650

1.054 (1.016-1.093)

0.005

0.589

0.832

0.763

0.0001

1.001 (0.997-1.005)

0.713

0.993 (0.990-0.997)

$<0.0001$

1.003 (0.994-1.012)

0.486

Pearson's correlation is shown on the left and multivariate association, adjusted for potential confounders are shown on the right. Only variables significant in Pearson's correlation were entered into the multivariate analysis. $P$-values are in bold to indicate statistical significance after adjustment. \#Gender was coded as a dummy variable where $1=$ female and $2=$ male. 'Ethnicity was coded as a dummy variable where $1=$ Chinese, $2=$ Malay, $3=$ Indian and $4=$ Others. \#PAD was coded as dummy variable where $0=$ no PAD and $1=$ PAD. * Retinopathy was coded as dummy variable where $0=$ no Retinopathy, $1=$ non-proliferative retinopathy and $2=$ proliferative retinopathy. $* *$ Metformin was coded as a dummy variable where $0=$ non-usage and 1 = usage. ^Log-transformed before analysis.

T2D. These findings suggest a potential pathogenic link between endothelin-1 and the development of clinical DPN. To our knowledge, while high endothelin-1 has been shown to predict incident coronary heart disease (24) and all-cause death in general population (25), this is the first report of elevated baseline endothelin-1 predicting incident DPN in a cohort of patients with T2D.

This study is the first to investigate baseline endothelin-1 with incident DPN using a prospective design. We hypothesize that ET1 may contribute to incident DPN through impact on several pathophysiological mechanisms. Elevated endothelin-1 has been found in both chronic and acute inflammatory demyelinating polyneuropathy compared to healthy controls (26). Most evidence suggests that actions attributed to endothelin-1 are likely to be secondary to reduced blood flow and ischemia of nerve tissue $(27,28)$. Apart from its vasoconstrictive actions, endothelin- 1 possesses pro-inflammatory effects in vascular walls. It has been reported that endothelin-1 activates macrophages, releasing mediators like TNF- $\alpha$ (29), IL-6 (30), IL-8 (31) and reactive oxidative species (ROS) (32). Endothelin-1 stimulates the production of ROS in arterial smooth muscle cells, endothelial cells and isolated arteries, demonstrating a putative mechanism for the detrimental effects of endothelin-1 on peripheral nerves $(33,34)$. Raised endothelin-1, at baseline, may directly potentiate the demyelination of peripheral nerves in patients with incident DPN. Direct neuronal actions of endothelin-1 are less well-studied compared to its vasomotor effects. In experimental diabetic models, endothelin receptor antagonism, with bosentan, led to a significant increase in sciatic nerve conduction through improvements in sciatic nutritive endoneurial blood flow (35). Novel therapies of $\mathrm{ET}_{\mathrm{A}}$ antagonists, such as Bosentan, led to improvements in microvascular endothelium-dependent vasodilatation in patients with diabetes and microangiopathy (36), 
Table 3 Multivariable Cox regression analysis predicting incident dabetic peripheral neuropathy.

\begin{tabular}{|c|c|c|}
\hline Variables & Hazards ratio $(95 \% \mathrm{Cl})$ & P-value \\
\hline \multicolumn{3}{|l|}{ Model } \\
\hline Endothelin-1 (pg/mL)^ & $4.345(1.451-13.009)$ & 0.009 \\
\hline Age (years) & $1.013(0.992-1.035)$ & 0.214 \\
\hline Gender ${ }^{\#}$ & $1.283(0.886-1.860)$ & 0.187 \\
\hline \multicolumn{3}{|c|}{ Ethnicity (Reference: Non-Malay) } \\
\hline Malay & $0.902(0.552-1.476)$ & 0.681 \\
\hline $\begin{array}{l}\text { Duration of Diabetes } \\
\text { (years) }\end{array}$ & $1.025(1.004-1.047)$ & 0.017 \\
\hline $\mathrm{Hba1c}(\%)$ & $1.148(0.988-1.333)$ & 0.071 \\
\hline SBP (10-unit) (mmHg) & $1.107(1.001-1.223)$ & 0.047 \\
\hline $\operatorname{eGFR}\left(\mathrm{mL} / \mathrm{min} / 1.73 \mathrm{~m}^{2}\right)$ & $0.996(0.989-1.003)$ & 0.217 \\
\hline Urine ACR $(\mathrm{mg} / \mathrm{g})^{\wedge}$ & $1.171(0.929-1.476)$ & 0.182 \\
\hline PAD vs no PAD & $1.448(0.892-2.350)$ & 0.135 \\
\hline $\begin{array}{l}\text { Retinopathy vs no } \\
\text { Retinopathy }\end{array}$ & $1.152(0.776-1.709)$ & 0.483 \\
\hline
\end{tabular}

Only parameters significant in Table 1 or known confounding factors were added sequentially into the Models. Age, gender, ethnicity and metabolic derangements which were significant in the univaraite analysis (diabetes duration, baseline $\mathrm{HbA} 1 \mathrm{c}$ and systolic BP), baseline eGFR, urinary ACR, $P A D$ and retinopathy status were included as covariates. Schoenfeld residual test: $P=0.2090$.

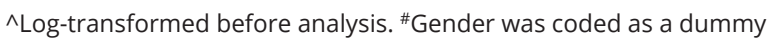
variable where $1=$ female and $2=$ male.

suggesting that higher endothelin-1 could contribute to poorer nerve conduction and DPN. On-going trial efforts, like SONAR (37), may provide better insights and possibilities of the endothelin receptor antagonism in improving blood pressure, reducing the incidence of DPN and diabetic ulcers.

Our study showed that elevated baseline blood pressure predicted incident DPN. Previous cross-sectional studies suggest a relationship between hypertension and the presence of neuropathy (38). A prospective cohort study identified hypertension as a vascular risk factor predicting the incidence of DPN in patients with Type 1 Diabetes (39). While the blood pressure lowering medication, angiotensin-converting enzyme inhibitors (ACEI), improved motor and sensory nerve conduction velocity in patients with diabetes (40), no differences were found in intensive and moderate blood pressure therapy on the progression of DPN in patients with T2D (41). In animal models of impaired glucose tolerance and hypertension, although neuropathy development was attributed to hyperglycemia, a combination of diabetes and hypertension led to worsening of sensory nerve function and development of myelin thinning and protein loss at late stages. These phenotypes are postulated to be associated with metalloproteinase dysregulation in Schwann cell (42). These findings are in line with our data that elevated blood pressure in patients with T2D accelerates DPN development. In our cohort, approximately $60 \%$ of patients were on ACEI and/ or angiotensin-receptor blocker (ARB) at baseline. Future studies on blood pressure trajectories might shed light on whether early blood-pressure lowering may delay onset of DPN.

Duration of diabetes was an independent predictor of incident DPN in our cohort, in line with data reported by others (43). In the univariate analyses, although HbA1c predicted incident DPN, it was attenuated in the fully adjusted model. This further supports the notion that duration of diabetes, rather than glycemic status, is a critical determinant in DPN pathogenesis. Indeed, while ACCORD showed that intensive glucoselowering reduced incident DPN (44), Steno-2 (45) and Veterans Affairs Diabetes Trial (VADT) (46) did not show a difference in development of DPN between groups with and without intensive glucose control. Having said so, we would concede that HBA1c observed at baseline may not be sufficient to capture global glycemic burden of the participants and may therefore explain the null association with incident DPN.

In our cohort, we showed that at baseline, older age, Malay ethnicity, higher BMI, elevated triglycerides and poorer eGFR were independently associated with endothelin-1, after adjustment for various risk factors. Endothelin-1 is a well-known marker for vascular endothelial dysfunction/inflammation, which has been reported to reduce availability of nitric oxide (47), in addition to its direct vasoconstriction effects. Therefore, a high plasma circulating endothelin-1, at baseline, could have been reflective of poorer endothelial function and increased the incidence of DPN, within a 3-year follow-up. Significant association of endothelin-1 with obesity (BMI and waist circumference) and triglycerides have been well-reported $(48,49)$. Impairment of glucose uptake by endothelin-1 (50) may reduce storage of glucosederived lipids. Although speculative, these mechanisms might lead to dyslipidemia as a result of dysfunctional adipocytes in an insulin resistant state. Congruent to this observation, intralipid infusion to increase triglyceride levels led to significant increase in arterial endothelin-1 in healthy volunteers (51). We showed an independent association of lower eGFR with baseline endothelin-1. The relationship between eGFR and endothelin-1 is not unexpected, as others have shown that higher baseline endothelin-1 predicted incident chronic kidney disease (CKD) (52). One possible mechanism which may explain the relationship of higher endothelin-1 and lower eGFR is the disruption of actin cytoskeleton in podocytes by 
endothelin-1, leading to increased permeability of the glomerular filtration barrier (53). Endothelin-1 may also induce endoplasmic reticulum stress and apoptosis in renal tubular cells, resulting in kidney injury (54). Significant association between Malay ethnicity and plasma endothelin-1 has never been reported before. While we previously showed that different genotypes of endothelin-1 may contribute to differences in plasma C-terminal pro-endothelin-1, conferring susceptibility to diabetic nephropathy, the study was conducted in a Chinese cohort (55). Large genotyping efforts, lifestyle and dietary habits will be required to decipher if plasma endothelin-1 is influenced by ethnicity. Future studies focused on genotyping of endothelin-1, lifestyle or dietary habits will be required to explore if plasma Endothelin-1 is influenced by ethnicity. While it is likely that endothelin-1 is a good predictor of incident DPN, its large variability in our multi-ethnic population may limit its use as a prognostic marker.

The pathogenesis of DPN in patients with T2D is complex. Whether elevated endothelin-1 is directly causal in the pathophysiological pathway of DPN or a surrogate indicator as a result of other diabetic complications at baseline is unknown. Recent publications support the prevailing hypothesis that small fiber nerve damage (affecting unmyelinated nerve ( $\mathrm{A} \delta$ and $\mathrm{C}$ ) fibers) precedes large fiber damage (myelinated (A $\alpha$ and $\mathrm{A} \beta$ ) in DPN (56, 57). Small fiber neuropathy usually affects nociceptive and autonomic systems, leading to microvascular dysfunction and impaired NO. In our study, small fiber neuropathy was not specifically assessed at baseline, hence we are not able to exclude the possibility that the presence of small fiber neuropathy led to an increase in endothelin-1 at baseline, which predicted incident DPN. We observed a marginally elevated heart rate, at baseline, in patients with incident DPN, which might reflect autonomic dysfunction, though this is highly speculative. Patients with incident DPN had multiple complications of $\mathrm{T} 2 \mathrm{D}$ at baseline. Raised endothelin-1 at baseline could be could be a consequence of compensatory response to retinopathy (58), increased arterial stiffness (59), endothelial dysfunction (11) or reduced renal clearance. Increased plasma endothelin- 1 has been previously linked to increased risk of microvascular and macrovascular complications such as microalbuminuria (60), PAD (61), while its expression in patients with diabetic proliferative retinopathy remains controversial $(62,63,64)$. These complications may collectively contribute to incident DPN, rather than endothelin-1, per se. Nonetheless, endothelin-1 remains an interesting early plasma biomarker, which may predict incident DPN.
Strengths of the study include the strict enrolment criteria, longitudinal design and the ability to perform detailed, careful and standardized assessment in a relatively large number of T2D patients. A second advantage is the ability to assess prognostic value of plasma endothelin-1 in a relatively large cohort of multi-ethnic patients with T2D. While we attempted to standardize blood collection after an overnight fast, we acknowledge that the limitation that we have only analyzed endothelin-1 in a T2D cohort at a single time point and our findings are not generalizeable to other populations. In vivo human glucose tolerance tests showed either a reduction (65) or no change of endothelin-1 (66), while fasting states in animal models led to raised plasma endothelin-1 (67). Given the possible influence on fasting changes of plasma endothelin-1, measuring at a single time point would not reflect the dynamic post-prandial changes. Additionally, we did not evaluate small-fibre neuropathy in our cohort, hence may underestimate the prevalence and incidence of neuropathy in our cohort. On entry, patients in our cohort had a diabetes duration of 10.0 years (4.0-16.0), hence our results cannot be applied to diabetes population at different stages. Due to the study protocol, time-toevent was estimated when patient was followed-up for the study; hence, the true incident date of onset may be not precise. A longer follow-up period, in future, will allow elucidation of other risk factors for incident DPN. Another limitation is that our study design of selecting patients from a non-randomized diabetes cohort does not allow us to preclude residual confounding effects.

In conclusion, this study demonstrated that baseline elevated baseline endothelin-1, SBP and longer duration of diabetes predicted incident DPN. Elucidating risk for DPN is important, given that some of these factors are potentially modifiable. The ability to recognize and stratify these patients, who may benefit from treatment, before the development of clinical symptoms will be beneficial.

\section{Supplementary materials}

This is linked to the online version of the paper at https://doi.org/10.1530/ EJE-19-0523.

\section{Declaration of interest}

The authors declare that there is no conflict of interest that could be perceived as prejudicing the impartiality of this study.

\section{Funding}

This research was supported by the Singapore Ministry of Health's National Medical Research Council under its CS-IRG (MOH-000066) and Alexandra Health Pte Ltd Endowment Fund SIGII/15202. 


\section{Acknowledgements}

The authors would like to acknowledge the research nurses and Mr Darren Yeo in the Clinical Research Unit of our institution, who helped with data collection and data entry, and thank all the patients who volunteered for this study.

\section{References}

1 GBD 2013 Mortality and Causes of Death Collaborators. Global, regional, and national age-sex specific all-cause and cause-specific mortality for 240 causes of death, 1990-2013: a systematic analysis for the Global Burden of Disease Study 2013. Lancet 2015385 117-171. (https://doi.org/10.1016/S0140-6736(14)61682-2)

2 Fowler MJ. Microvascular and macrovascular complications of diabetes. Clinical Diabetes 200826 77-82. (https://doi.org/10.2337/ diaclin.26.2.77)

3 Zhou J \& Zhou S. Inflammation: therapeutic targets for diabetic neuropathy. Molecular Neurobiology 201449 536-546. (https://doi. org/10.1007/s12035-013-8537-0)

4 Callaghan BC, Little AA, Feldman EL \& Hughes RA. Enhanced glucose control for preventing and treating diabetic neuropathy. Cochrane Database of Systematic Reviews 2012 CD007543. (https://doi. org/10.1002/14651858.CD007543.pub2)

5 Ferrannini E \& DeFronzo RA. Impact of glucose-lowering drugs on cardiovascular disease in type 2 diabetes. European Heart Journal 2015 36 2288-2296. (https://doi.org/10.1093/eurheartj/ehv239)

6 Gaede P, Oellgaard J, Carstensen B, Rossing P, Lund-Andersen H, Parving $\mathrm{HH} \&$ Pedersen $\mathrm{O}$. Years of life gained by multifactorial intervention in patients with type 2 diabetes mellitus and microalbuminuria: 21 years follow-up on the Steno- 2 randomised trial. Diabetologia 201659 2298-2307. (https://doi.org/10.1007/ s00125-016-4065-6)

7 Stirban A. Microvascular dysfunction in the context of diabetic neuropathy. Current Diabetes Reports 201414 541. (https://doi. org/10.1007/s11892-014-0541-x)

8 Wheatcroft SB, Williams IL, Shah AM \& Kearney MT. Pathophysiological implications of insulin resistance on vascular endothelial function. Diabetic Medicine 200320 255-268. (https:// doi.org/10.1046/j.1464-5491.2003.00869.x)

9 De Vriese AS, Verbeuren TJ, Van de Voorde J, Lameire NH \& Vanhoutte PM. Endothelial dysfunction in diabetes. British Journal of Pharmacology 2000130 963-974. (https://doi.org/10.1038/ sj.bjp.0703393)

10 Green AQ, Krishnan S, Finucane FM \& Rayman G. Altered C-fiber function as an indicator of early peripheral neuropathy in individuals with impaired glucose tolerance. Diabetes Care 201033 174-176. (https://doi.org/10.2337/dc09-0101)

11 Pek SLT, Sum CF, Yeoh LY, Lee SBM, Tang WE, Lim SC \& Tavintharan S. Association of apolipoprotein-CIII (ApoC-III), endothelium-dependent vasodilation and peripheral neuropathy in a multi-ethnic population with type 2 diabetes. Metabolism: Clinical and Experimental 201772 75-82. (https://doi.org/10.1016/j. metabol.2017.03.016)

12 Yanagisawa M, Kurihara H, Kimura S, Tomobe Y, Kobayashi M, Mitsui Y, Yazaki Y, Goto K \& Masaki T. A novel potent vasoconstrictor peptide produced by vascular endothelial cells. Nature 1988332 411-415. (https://doi.org/10.1038/332411a0)

13 Giaid A, Gibson SJ, Ibrahim BN, Legon S, Bloom SR, Yanagisawa M, Masaki T, Varndell IM \& Polak JM. Endothelin 1, an endotheliumderived peptide, is expressed in neurons of the human spinal cord and dorsal root ganglia. PNAS 198986 7634-7638. (https://doi. org/10.1073/pnas.86.19.7634)

14 Kohan DE, Inscho EW, Wesson D \& Pollock DM. Physiology of endothelin and the kidney. Comprehensive Physiology 20111 883-919. (https://doi.org/10.1002/cphy.c100039)
15 Ferri C, Carlomagno A, Coassin S, Baldoncini R, Cassone Faldetta MR, Laurenti O, Properzi G, Santucci A \& De Mattia G. Circulating endothelin-1 levels increase during euglycemic hyperinsulinemic clamp in lean NIDDM men. Diabetes Care 199518 226-233. (https://doi.org/10.2337/diacare.18.2.226)

16 Ferri C, Bellini C, Desideri G, Di Francesco L, Baldoncini R, Santucci A \& De Mattia G. Plasma endothelin-1 levels in obese hypertensive and normotensive men. Diabetes $1995 \mathbf{4 4} 431-436$. (https://doi.org/10.2337/diab.44.4.431)

17 Kohno M, Yasunari K, Murakawa K, Yokokawa K, Horio T, Fukui T \& Takeda T. Plasma immunoreactive endothelin in essential hypertension. American Journal of Medicine 199088 614-618. (https:// doi.org/10.1016/0002-9343(90)90527-k)

18 Miyauchi T, Yanagisawa M, Tomizawa T, Sugishita Y, Suzuki N, Fujino M, Ajisaka R, Goto K \& Masaki T. Increased plasma concentrations of endothelin-1 and big endothelin-1 in acute myocardial infarction. Lancet 19892 53-54. (https://doi.org/10.1016/ s0140-6736(89)90303-6)

19 Pek SL, Tavintharan S, Wang X, Lim SC, Woon K, Yeoh LY, Ng X, Liu J \& Sum CF. Elevation of a novel angiogenic factor, leucine-richalpha2-glycoprotein (LRG1), is associated with arterial stiffness, endothelial dysfunction, and peripheral arterial disease in patients with type 2 diabetes. Journal of Clinical Endocrinology and Metabolism 2015100 1586-1593. (https://doi.org/10.1210/jc.2014-3855)

20 Liu JJ, Pek SLT, Ang K, Tavintharan S, Lim SC \& SMART2D Study. Plasma leucine-rich alpha-2-glycoprotein 1 predicts rapid eGFR decline and albuminuria progression in type 2 diabetes mellitus. Journal of Clinical Endocrinology and Metabolism 2017102 3683-3691. (https://doi.org/10.1210/jc.2017-00930)

21 Levey AS, Stevens LA, Schmid CH, Zhang YL, Castro 3rd AF, Feldman HI, Kusek JW, Eggers P, Van Lente F, Greene T et al. A new equation to estimate glomerular filtration rate. Annals of Internal Medicine 2009150 604-612. (https://doi.org/10.7326/0003-4819150-9-200905050-00006)

22 Wallace TM, Levy JC \& Matthews DR. Use and abuse of HOMA modeling. Diabetes Care 200427 1487-1495. (https://doi. org/10.2337/diacare.27.6.1487)

23 Tavintharan S, Woon K, Pek LT, Jauhar N, Dong X, Lim SC \& Sum CF. Niacin results in reduced monocyte adhesion in patients with type 2 diabetes mellitus. Atherosclerosis 2011215 176-179. (https://doi. org/10.1016/j.atherosclerosis.2010.12.020)

24 Daka B, Olausson J, Larsson CA, Hellgren MI, Rastam L, Jansson PA \& Lindblad U. Circulating concentrations of endothelin-1 predict coronary heart disease in women but not in men: a longitudinal observational study in the Vara-Skovde Cohort. BMC Cardiovascular Disorders 201515 146. (https://doi.org/10.1186/s12872-015-0141-y)

25 Yokoi K, Adachi H, Hirai Y, Enomoto M, Fukami A, Ogata K, Tsukagawa E, Kasahara A \& Imaizumi T. Plasma endothelin-1 level is a predictor of 10 -year mortality in a general population: the Tanushimaru study. Circulation Journal 201276 2779-2784. (https:// doi.org/10.1253/circj.cj-12-0469)

26 Chang CW, Wu HC, Lyu RK, Lo YS, Chen CM, Ro LS, Chang HS, Huang CC, Liao MF, Wu YR et al. Elevated serum levels of endothelin-1 in patients with chronic inflammatory demyelinating polyneuropathy. Clinica Chimica Acta 2018476 49-53. (https://doi. org/10.1016/j.cca.2017.11.008)

27 Rebello S, Roy S, Saxena PR \& Gulati A. Systemic hemodynamic and regional circulatory effects of centrally administered endothelin-1 are mediated through eta receptors. Brain Research 1995676 141-150. (https://doi.org/10.1016/0006-8993(95)00107-2)

28 Gulati A, Kumar A, Morrison S \& Shahani BT. Effect of centrally administered endothelin agonists on systemic and regional blood circulation in the rat: role of sympathetic nervous system. Neuropeptides 199731 301-309. (https://doi.org/10.1016/s01434179(97)90063-9)

29 Ruetten H \& Thiemermann C. Endothelin-1 stimulates the biosynthesis of tumour necrosis factor in macrophages: ET-receptors, 
signal transduction and inhibition by dexamethasone. Journal of Physiology and Pharmacology 199748 675-688.

30 Browatzki M, Schmidt J, Kubler W \& Kranzhofer R. Endothelin-1 induces interleukin- 6 release via activation of the transcription factor NF-kappaB in human vascular smooth muscle cells. Basic Research in Cardiology 200095 98-105. (https://doi.org/10.1007/s003950050170)

31 Hofman FM, Chen P, Jeyaseelan R, Incardona F, Fisher M \& Zidovetzki R. Endothelin-1 induces production of the neutrophil chemotactic factor interleukin-8 by human brain-derived endothelial cells. Blood 199892 3064-3072.

32 Kowalczyk A, Kleniewska P, Kolodziejczyk M, Skibska B \& Goraca A. The role of endothelin-1 and endothelin receptor antagonists in inflammatory response and sepsis. Archivum immunologiae et therapiae experimentalis 201563 41-52. (https://doi.org/10.1007/s00005-0140310-1)

33 Dong F, Zhang X, Wold LE, Ren Q, Zhang Z \& Ren J. Endothelin-1 enhances oxidative stress, cell proliferation and reduces apoptosis in human umbilical vein endothelial cells: role of ETB receptor, NADPH oxidase and caveolin-1. British Journal of Pharmacology 2005145 323-333. (https://doi.org/10.1038/sj.bjp.0706193)

34 Laplante MA, Wu R, Moreau P \& de Champlain J. Endothelin mediates superoxide production in angiotensin II-induced hypertension in rats. Free Radical Biology and Medicine 200538 589-596. (https://doi.org/10.1016/j.freeradbiomed.2004.11.026)

35 Stevens EJ \& Tomlinson DR. Effects of endothelin receptor antagonism with bosentan on peripheral nerve function in experimental diabetes. British Journal of Pharmacology 1995115 373-379. (https://doi.org/10.1111/j.1476-5381.1995.tb15888.x)

36 Rafnsson A, Bohm F, Settergren M, Gonon A, Brismar K \& Pernow J. The endothelin receptor antagonist bosentan improves peripheral endothelial function in patients with type 2 diabetes mellitus and microalbuminuria: a randomised trial. Diabetologia 201255 600-607. (https://doi.org/10.1007/s00125-011-2415-y)

37 Heerspink HJL, Andress DL, Bakris G, Brennan JJ, Correa-Rotter R, Hou FF, Kitzman DW, Kohan D, Makino H, McMurray J et al. Baseline characteristics and enrichment results from the SONAR trial. Diabetes, Obesity and Metabolism 201820 1829-1835. (https://doi. org/10.1111/dom.13315)

38 Knuiman MW, Welborn TA, McCann VJ, Stanton KG \& Constable IJ. Prevalence of diabetic complications in relation to risk factors. Diabetes 198635 1332-1339. (https://doi.org/10.2337/diab.35.12.1332)

39 Tesfaye S, Chaturvedi N, Eaton SE, Ward JD, Manes C, IonescuTirgoviste C, Witte DR, Fuller JH \& EURODIAB Prospective Complications Study Group. Vascular risk factors and diabetic neuropathy. New England Journal of Medicine 2005352 341-350. (https://doi.org/10.1056/NEJMoa032782)

40 Malik RA, Williamson S, Abbott C, Carrington AL, Iqbal J, Schady W \& Boulton AJ. Effect of angiotensin-converting-enzyme (ACE) inhibitor trandolapril on human diabetic neuropathy: randomised double-blind controlled trial. Lancet 1998352 1978-1981. (https:// doi.org/10.1016/S0140-6736(98)02478-7)

41 Estacio RO, Jeffers BW, Gifford N \& Schrier RW. Effect of blood pressure control on diabetic microvascular complications in patients with hypertension and type 2 diabetes. Diabetes Care 200023 (Supplement 2) B54-B64

42 De Visser A, Hemming A, Yang C, Zaver S, Dhaliwal R, Jawed Z \& Toth $C$. The adjuvant effect of hypertension upon diabetic peripheral neuropathy in experimental type 2 diabetes. Neurobiology of Disease 201462 18-30. (https://doi.org/10.1016/j.nbd.2013.07.019)

43 Young MJ, Boulton AJ, MacLeod AF, Williams DR \& Sonksen PH. A multicentre study of the prevalence of diabetic peripheral neuropathy in the United Kingdom hospital clinic population. Diabetologia 199336 150-154. (https://doi.org/10.1007/bf00400697)

44 Ismail-Beigi F, Craven T, Banerji MA, Basile J, Calles J, Cohen RM, Cuddihy R, Cushman WC, Genuth S, Grimm Jr RH et al. Effect of intensive treatment of hyperglycaemia on microvascular outcomes in type 2 diabetes: an analysis of the accord randomised trial. Lancet 2010376 419-430. (https://doi.org/10.1016/S0140-6736(10)60576-4)

45 Gaede P, Vedel P, Larsen N, Jensen GV, Parving HH \& Pedersen O. Multifactorial intervention and cardiovascular disease in patients with type 2 diabetes. New England Journal of Medicine $2003 \mathbf{3 4 8}$ 383-393. (https://doi.org/10.1056/NEJMoa021778)

46 Duckworth W, Abraira C, Moritz T, Reda D, Emanuele N, Reaven PD, Zieve FJ, Marks J, Davis SN, Hayward R et al. Glucose control and vascular complications in veterans with type 2 diabetes. New England Journal of Medicine 2009360 129-139. (https://doi.org/10.1056/ NEJMoa0808431)

47 Mather KJ, Mirzamohammadi B, Lteif A, Steinberg HO \& Baron AD. Endothelin contributes to basal vascular tone and endothelial dysfunction in human obesity and type 2 diabetes. Diabetes 200251 3517-3523. (https://doi.org/10.2337/diabetes.51.12.3517)

48 van Harmelen V, Eriksson A, Astrom G, Wahlen K, Naslund E, Karpe F, Frayn K, Olsson T, Andersson J, Ryden M et al. Vascular peptide endothelin-1 links fat accumulation with alterations of visceral adipocyte lipolysis. Diabetes 200857 378-386. (https://doi. org/10.2337/db07-0893)

49 Eriksson AK, van Harmelen V, Stenson BM, Astrom G, Wahlen K, Laurencikiene J \& Ryden M. Endothelin-1 stimulates human adipocyte lipolysis through the $\mathrm{ET}_{\mathrm{A}}$ receptor. International Journal of Obesity 200933 67-74. (https://doi.org/10.1038/ijo.2008.212)

50 Shemyakin A, Salehzadeh F, Bohm F, Al-Khalili L, Gonon A, Wagner H, Efendic S, Krook A \& Pernow J. Regulation of glucose uptake by endothelin-1 in human skeletal muscle in vivo and in vitro. Journal of Clinical Endocrinology and Metabolism 201095 2359-2366. (https://doi.org/10.1210/jc.2009-1506)

51 Piatti PM, Monti LD, Conti M, Baruffaldi L, Galli L, Phan CV, Guazzini B, Pontiroli AE \& Pozza G. Hypertriglyceridemia and hyperinsulinemia are potent inducers of endothelin-1 release in humans. Diabetes 199645 316-321. (https://doi.org/10.2337/ diab.45.3.316)

52 Rebholz CM, Harman JL, Grams ME, Correa A, Shimbo D, Coresh J $\&$ Young BA. Association between Endothelin-1 levels and kidney disease among blacks. Journal of the American Society of Nephrology 201728 3337-3344. (https://doi.org/10.1681/ASN.2016111236)

53 Saleh MA, Boesen EI, Pollock JS, Savin VJ \& Pollock DM. Endothelin-1 increases glomerular permeability and inflammation independent of blood pressure in the rat. Hypertension 201056 942-949. (https://doi.org/10.1161/HYPERTENSIONAHA.110.156570)

54 De Miguel C, Pollock DM \& Pollock JS. Endothelium-derived ET-1 and the development of renal injury. American Journal of Physiology: Regulatory, Integrative and Comparative Physiology 2015309 R1071-R1073. (https://doi.org/10.1152/ajpregu.00142.2015)

55 Lim SC, Liu JJ, Low HQ, Morgenthaler NG, Li Y, Yeoh LY, Wu YS, Goh SK, Chionh CY, Tan SH et al. Microarray analysis of multiple candidate genes and associated plasma proteins for nephropathy secondary to type 2 diabetes among Chinese individuals. Diabetologia 200952 1343-1351. (https://doi.org/10.1007/s00125-009-1368-x)

56 Smith AG, Ramachandran P, Tripp S \& Singleton JR. Epidermal nerve innervation in impaired glucose tolerance and diabetes-associated neuropathy. Neurology 200157 1701-1704. (https://doi.org/10.1212/ wnl.57.9.1701)

57 Sumner CJ, Sheth S, Griffin JW, Cornblath DR \& Polydefkis M. The spectrum of neuropathy in diabetes and impaired glucose tolerance. Neurology 200360 108-111. (https://doi.org/10.1212/wnl.60.1.108)

58 Takagi C, Bursell SE, Lin YW, Takagi H, Duh E, Jiang Z, Clermont AC $\&$ King GL. Regulation of retinal hemodynamics in diabetic rats by increased expression and action of endothelin-1. Investigative Ophthalmology and Visual Science 199637 2504-2518.

59 Vuurmans TJ, Boer P \& Koomans HA Effects of endothelin-1 and endothelin-1 receptor blockade on cardiac output, aortic pressure, and pulse wave velocity in humans. Hypertension $2003 \mathbf{4 1}$ 1253-1258. (https://doi.org/10.1161/01.HYP.0000072982.70666.E8) 
60 De Mattia G, Cassone-Faldetta M, Bellini C, Bravi MC, Laurenti O, Baldoncini R, Santucci A \& Ferri C. Role of plasma and urinary endothelin-1 in early diabetic and hypertensive nephropathy. American Journal of Hypertension 199811 983-988. (https://doi. org/10.1016/s0895-7061(98)00094-6)

61 Mangiafico RA, Malatino LS, Santonocito M, Sarnataro F, Dell'Arte S, Messina R \& Santangelo B. Plasma endothelin-1 levels in patients with peripheral arterial occlusive disease at different Fontaine's stages. Panminerva Medica 199941 22-26.

62 Adamiec-Mroczek J, Oficjalska-Mlynczak J \& Misiuk-Hojlo M. Roles of endothelin- 1 and selected proinflammatory cytokines in the pathogenesis of proliferative diabetic retinopathy: analysis of vitreous samples. Cytokine 201049 269-274. (https://doi. org/10.1016/j.cyto.2009.11.004)

63 Hernandez C, Rodriguez B, Losada E, Corraliza L, Garcia-Ramirez M $\&$ Simo R. Normoalbuminuric type 1 diabetic patients with retinopathy have an impaired tubular response to desmopressin: its relationship with plasma endothelin-1. Journal of Clinical
Endocrinology and Metabolism 200994 2060-2065. (https://doi. org/10.1210/jc.2008-2784)

64 Kawamura M, Ohgawara H, Naruse M, Suzuki N, Iwasaki N, Naruse K, Hori S, Demura H \& Omori Y. Increased plasma endothelin in NIDDM patients with retinopathy. Diabetes Care 199215 1396-1397. (https://doi.org/10.2337/diacare.15.10.1396)

65 DeLoach S, Huan Y, Daskalakis C \& Falkner B. Endothelin-1 response to glucose and insulin among African Americans. Journal of the American Society of Hypertension 20104 227-235. (https://doi. org/10.1016/j.jash.2010.07.004)

66 Leyva F, Wingrove C, Felton C \& Stevenson JC. Physiological hyperinsulinemia is not associated with alterations in venous plasma levels of endothelin-1 in healthy individuals. Metabolism 199746 1137-1139. (https://doi.org/10.1016/S0026-0495(97)90205-5)

67 Mehta RS \& Hartle DK. Effects of total fasting or chronic food restriction on plasma endothelin levels in rats. Physiology and Behavior 199456 407-410. (https://doi.org/10.1016/00319384(94)90214-3)

Received 8 July 2019

Revised version received 23 January 2020

Accepted 11 Febraury 2020 